\title{
The Effect of Premarital Cohabitation on Marital Stability over the Duration of Marriage
}

\author{
Ronald A. Budinski \\ Research and Analysis Branch \\ Statistics Canada \\ Ottawa, Ontario, Canada \\ Frank Trovato \\ Department of Sociology \\ and Population Research Laboratory \\ University of Alberta \\ Edmonton, Alberta, Canada
}

\begin{abstract}
Research has shown that premarital cohabitors who eventually marry are more likely to divorce or separate than persons who do not cohabit prior to marriage. This study investigates the possibility that the difference in marital stability between cohabitors and non-cohabitors may change with increasing duration of marriage. Using Canadian 1995 General Social Survey data, various Proportional Hazards Models were specified to compare the marital dissolution risks of cohabitors and non-cohabitors, while controlling for a set of relevant factors. Initially, it was found that both groups had virtually identical dissolution risks. However, further specification of the hazards model indicated that indeed cohabitors have a greater risk of marital dissolution than noncohabitors. Further tests to differentiate between short- and long-term unions indicated that premarital cohabitors have a greater dissolution risk in the first ten years of their union, while non-cohabitors have a greater hazard after ten years of marriage. We discuss these findings in the context of the North American based literature on cohabitation and marriage dissolution, and offer suggestions for further study.
\end{abstract}

Key Words: Cohabitation, marriage, marital dissolution 
Ronald A. Budinski and Frank Trovato

\section{Résumé}

Plusieurs recherches ont démontré que les couples qui cohabitent avant le mariage et qui finissent par se marier courent un risque plus élevé de divorce ou de séparation que les couples qui ne cohabitent pas avant le mariage. Cette étude examine l'hypothèse que cette différence dans la stabilité des mariages entre les couples cohabitant et les couples non-cohabitant pourrait changer suivant la durée du mariage. En s'appuyant sur les données de l'Enquête sociale générale canadienne de 1995, différents modèles de régression à effet proportionnel ont été spécifiés pour comparer les risques de dissolution des mariages dans les couples cohabitant et les couples non-cohabitant. D'autres études qui ont été menées pour déterminer s'il y avait des différences entre les unions à court terme et les unions à long terme indiquent que les couples cohabitant courent un plus grand risque de dissolution durant les dix premières années de mariage tandis que les couples non-cohabitant courent un plus grand risque après les dix premières années de mariage. Cet article explore ces résultats dans le contexte de la documentation nord-américaine sur la cohabitation et la dissolution des mariages et suggère de nouvelles avenues pour de plus amples études.

Mots clés : La cohabitation, le mariage, la dissolution des mariages.

\section{Introduction}

In most industrialized countries the growing legitimization of cohabitation has made it almost an expected stage in the marriage process. Among the young cohabitation is being increasingly viewed as a substitute for marriage. One important observation in virtually all of the research on this subject is that premarital cohabitation is usually associated with marital instability---cohabiting couples that marry are more likely than non-cohabiting couples to end their marriage in separation or divorce. The trend toward cohabitation does not appear to be letting up in Western countries. With increased incidence, this type of relationship has essentially lost its "deviant" stigma, and in fact most young adults now hold positive attitudes toward cohabitation (DeMaris and Rao 1992; Thornton, Axin and Hill, 1992). One question that has been touched upon in this literature, but not fully explored in the Canadian context, is whether the "cohabitation effect" is duration-dependent. In other words, do premarital cohabitors experience a continually greater risk of marital breakdown than do couples that have never cohabited before marriage, whether the marriage has 
lasted three years or thirty years? If not, does the difference in marital dissolution risk between cohabitors and non-cohabitors converge over time, until some point in the duration of marriage is reached in which premarital cohabitation no longer appears to have any destabilizing effect? Or is the opposite true---i.e. does the risk of dissolution between cohabitors and noncohabitors actually diverge over marital duration?

The purpose of this study is to determine if in fact a marital duration-dependent effect of premarital cohabitation exists. If it does exist, what are the explanations for it? Are there other factors associated with marriage that may affect the marriages of cohabitors and non- cohabitors differently, at different durations of a marital union? Determining typical marital outcomes of cohabitors enables researchers to understand how the cohabiting relationship is evolving and growing in Western society. Some possible outcomes, consistent with previous research, are: (1) premarital cohabitation is negatively associated with marital stability. That is to say, the probability of marital dissolution due to divorce or separation would be greater for those who cohabited before marriage than those who did not; (2) the probability of dissolution is greater for cohabitors only at early marital durations; that is, the "risk gap" between cohabitors and noncohabitors declines with time spent in marriage, until a point is reached where there is no significant difference; (3) the probability of marital break up is greater for cohabitors only at later durations; that is to say, there is no significant difference in early durations; (4) the probability of marital dissolution is not significantly different for cohabitors and non-cohabitors at any duration of marriage; (5) premarital cohabitation is positively associated with marital stability, and the probability of marital disruption is greater for non-cohabitors, at any marital duration.

\section{Background}

The rise in cohabitation rates over the last three decades in Western countries has been well documented (e.g. Axinn and Thornton, 1996; Balakrishnan, Lapierre-Adamcyk, and Krotki 1993; Bennett, Blanc and Bloom 1988; Bumpass and Sweet 1989; LeBourdais, Neill, and Vachon 2000; Rindfuss and VandenHeuvel, 1990; Smock 2000). Its growing prevalence is, in part, a phase in the ongoing social transformation of the Western family, preceded by declining marriage and fertility rates, postponement of marriage, and increasing divorce rates. Cohabitation may in fact be a reaction to the declining marital rates and rising divorce rates, and the sense that marriage is an increasingly fragile union (Axinn and Thornton 1992, 1996; Lillard, Brien, and Waite 1995; Rao 1988). 
Ronald A. Budinski and Frank Trovato

For couples that do not feel confident about creating an enduring marital relationship, cohabitation is a viable alternative. Many components of marriage are present in cohabiting unions, such as sharing of home, economic resources, sexual intimacy, and (increasingly in recent years) childbearing. It is true that cohabitation is generally much easier to dissolve than legal marriage; but for many modern couples it appears to provide the best of both worlds: the freedom and independence associated with singlehood, and the emotional, sexual, and economic advantages of marriage.

At the same time, the literature has established that cohabitation tends to be transient and short-lived (Balakrishnan et al. 1993; Burch 1989; Teachman and Polonko 1990). Cohabiting unions may dissolve by marriage of the couple or by separation ${ }^{1}$, but even when marriage is the result, the relationship often remains unstable, with a greater likelihood of marital breakdown (Axinn and Thornton 1992, 1996; Bennett et al. 1988; Lillard et al. 1995; Trussell and Rao 1989; Teachman and Polonko 1990; Thomson and Colella 1992).

Why is cohabitation associated so closely with instability in a relationship? One possible reason could be that cohabitors are generally a select group of individuals possessing characteristics that are not conducive to a stable relationship. This is known as the "selectivity" thesis (Bennett et al. 1988; DeMaris and Rao 1992; Lillard, Brien and Waite, 1995; Nock 1995). Alternatively, time spent in a cohabiting union may help to develop negative attitudes toward marriage and positive attitudes toward divorce - the "experience" theory (Axinn and Thornton 1992; Nock 1995; Schoen 1992). Research on the stability of both cohabitation and marriages preceded by cohabitation has lent support to the both these theories. For example, it has been suggested that cohabitation selects individuals who have a weaker commitment to the institution of marriage: they tend to be less committed to marriage and more tolerant of divorce (Bennett et al. 1988; Lillard et al. 1995), and generally express less positive attitudes about their relationship as compared to married couples (Nock 1995; Thomson and Colella 1992). Cohabitors also tend to express lower levels of happiness and interaction with their partners and higher levels of disagreement and conflict (Booth and Johnson 1988). Those cohabitors that marry report lower quality marriages, with greater likelihood of divorce, than those who enter directly into marriage (Thomson and Colella 1992). Rather than being one-half of a couple, cohabitors may retain their "individualness" even within a marriage, and consider themselves more self-reliant and less dependent on a marital relationship for support and intimacy (Newcomb and Bentler 1980) ${ }^{2}$.

Recent evidence suggests that attitudes toward marriage and divorce among couples that use cohabitation as a springboard to marriage are converging with 
those of non-cohabiting married couples. LeBourdais, Neill, and Vachon (2000) indicate that among recent cohorts in Canada, the marital dissolution rates of premarital cohabitors are becoming similar to those of couples who did not cohabit before marriage.

Some research has touched on the possibility that premarital cohabitation may have a varying effect upon marital stability over the course of a marriage, but discussion has been rather limited, as this is typically not the central focus of such studies. Results have also been inconclusive. Using data from a Swedish survey on women conducted in 1981, Bennett and associates (1988) found that the hazard of marital dissolution for cohabitors was greater than it was for noncohabitors until the first eight years of marriage, with only small and insignificant risk differences for both groups after this time. This is in contrast to the results of Teachman and Polonko (1990), who looked at the National Longitudinal Study of the High School Class of 1972, conducted in the United States in 1986. According to their results, premarital cohabitation had little effect before the first ten years of marriage, but after this time, cohabitors were more likely to experience marital dissolution than noncohabitors. When controlling for duration, however, no significant differences in marital disruption between the two groups were found.

Using the same data, Lillard and associates (1995) showed that, for both cohabitors and non-cohabitors, the risk of marital disruption rises quite significantly during the first few years of marriage, and then increases at a slower rate thereafter. From the 1987-88 National Survey of Families and Households, Schoen (1992) found that the differential risk of dissolution is greater for cohabitors during the early years of marriage only, while DeMaris and Rao (1992) noted that marital dissolution is much more likely among cohabitors than non-cohabitors at any marital duration.

Canadian research on the issue is also inconclusive. White (1987) analyzed data from the 1984 Family History Survey and found---contrary to almost all other studies on the subject---that premarital cohabitation had a positive effect on marital stability, even after controlling for marital duration. He argued that cohabitation might aid marital stability, even in the early years of marriage, because it delays the age at marriage and allows couples more time to mature. However, Trussell and Rao (1989) noted a fault in White's methodology and concluded that using proper methods, White would have come to the opposite conclusion with the same data-that premarital cohabitation leads to greater risk of subsequent marital dissolution. Using ordinary life table techniques, Wu (2000) found that premarital cohabitation is related to a greater probability of marital dissolution, but the probability is constant over marital duration. Balakrishnan, Rao, Lapierre-Adamcyk, and Krotki (1987) showed that for 
Canadian women aged 18-49 the proportion of marriages ending in dissolution was higher at all marital durations for cohabiting than for non-cohabiting women, though the difference appeared to increase proportionally with time spent in marriage. In the United States, Bennett and associates (1988) have suggested that after a certain number of years in marriage, those cohabiting women who have a propensity to divorce had already done so, leaving the more stable cohabitors remaining in marriage. Morgan and Rindfuss (1985) have argued that as a marriage cohort ages, a selection process occurs so that the strongest marriages survive, thus reducing the probability of marital disruption over time. It is likely that the amount invested into the marriage by each spouse increases with time in the relationship, which may reduce the risk of disruption.

Considering this research, one might expect that marriages between cohabitors would initially be much less stable than marriages between non-cohabitors, and perhaps over time, marital stability between the two groups would tend to converge, since a far greater number of cohabitation-preceded marriages would be "weeded out" early on, as it were. This is the second of the five marital outcomes outlined earlier. The other outcomes would seem less likely, if we believe that cohabitors have a greater risk of marital disruption than noncohabitors have. Cohabitors who have managed to reach longer marital durations would have invested much time and effort and presumably also demonstrated a strong commitment to marriage, so that after a certain number of years of marriage they may not face a significantly greater risk of dissolution than non-cohabitors would.

\section{Hypotheses}

As we have seen, previous research has provided strong evidence that couples that cohabit before marriage are more likely to divorce or separate than couples that did not cohabit. Results as to whether cohabitation has a stronger or weaker effect over time in marriage have been inconclusive. As Mills and Trovato (2000) reason, transaction costs of dissolution become greater than benefits when investment into the relationship increases. Premarital cohabitors who manage to remain together would logically increase their investment into the relationship over time, in the form of stronger emotional ties, mutual friends, material goods, and possibly children. We would therefore expect the gap in the hazard of dissolution between cohabiting and non-cohabiting married couples in Canada to be reduced over time. Thus the expectations of the current analysis are that:

(1) premarital cohabitation leads to a greater risk of marital dissolution by separation or divorce than if cohabitation had not occurred; 

separation or divorce weakens with time spent in marriage, to the point that it is no longer significant. At no point in marriage, however, does cohabitation lead to a lesser risk of dissolution than if cohabitation had not occurred.

\section{Data and Methods}

This study uses data from the 1995 Canadian General Social Survey, Cycle 10: The Family (GSS-95). The core content component of Cycle 10 relates to family, and includes items on marital and cohabiting union histories, childbearing histories, fertility intentions, and attitudinal variables relating to gender roles and family. The target population of GSS-95 was all persons 15 years of age and older in Canada, with the exception of residents of the Yukon and Northwest Territories, and full-time residents of institutions. In total, 10,749 respondents from across the ten Canadian provinces completed the full questionnaire. ${ }^{3}$ The overall response rate was 81 percent. (Statistics Canada 1997).

Because of the obvious association of age with second or higher ranked unions, only first unions are to be considered here, so that each of the 10,749 respondents has no more than one possible data record from the union file. The subsample for this study excludes all respondents who have never been in a marital union, including those who had cohabited but not married. A total of 7,187 data records, or $66.9 \%$ of the survey sample, remained for analysis.

Our multivariate analysis is based on Proportional Hazards (PH) models (Cox 1972). The PH model has a distinct advantage over the more basic life table method: it is a continuous-time model, whereas the life table method assumes that time-dependent measures such as age or marital duration are divided into sets of discrete intervals (Teachman 1982). There are two main functions in the PH model: the hazard function and the survival function. The hazard function represents the probability of the event of interest occurring at time $t$, while controlling for a set of $k$ covariates. One other advantage of the PH model is that it does not make the assumption of population homogeneity, as is usually done in the actuarial life table. In the PH model, values of the hazard function, $h(t, \mathbf{X})$, differ by groups of individuals with dissimilar values of covariates. ${ }^{4}$ The core assumptions in the PH Model are that population heterogeneity is captured by the set of covariates in the model, and relative risks remain constant over time. Specific values of the hazard function are calculated on the basis of a baseline function. That is, the risk of marital dissolution of subgroups can be estimated 
relative to the reference group, once the hazard function is calculated for various durations of the unions in question (Teachman 1982).

If the hazard function defines probability of marital dissolution, the survival function represents the probability of a marital union surviving at least to duration $t$. The survival function can be derived from the hazard function (Hinde 1999, pp. 62-76). The PH model assumes that relative risks remain constant over time. In practice, however, certain covariates may interact with time (i.e. the risk varies with time). Thus, it is possible to extend the $\mathrm{PH}$ model to allow for timedependent covariates. The hazard function specified for this study is

$$
h(t, \mathbf{X}(t))=h_{0}(t) \exp \left[\sum_{i=1}^{p} \beta_{i} \mathrm{X}_{i}+\sum_{j=1}^{q} \delta_{j} \mathrm{X}_{j}(g(t))\right],
$$

consisting of a duration-dependent baseline hazard function $h_{0}(t)$ multiplied by an exponential function containing $p$ time-independent covariates and $q$ timedependent covariates, together with their respective and $\delta$ coefficients. The time-dependent covariates are interacting with time, specified as function $g(t)$ (Kleinbaum 1997). This function is commonly either linear time $t, \log t$, or $t^{2}$. Another possibility, used in this study, is to divide time into specified intervals where it is assumed that the hazard is constant only across each interval, so that in time interval $\left(t_{0}, t_{1}\right), g(t)$ is equal to 1 when $t_{0}<t<t_{1}$, and is zero otherwise.

A common problem in survival analysis is the issue of censoring. Rightcensoring occurs when either (1) the individual does not experience the event of interest before the study ends, (2) the individual is lost to follow-up during the course of the study, or (3) the individual withdraws from the study before it is completed, due to death or some other cause. Left censoring occurs when the individual's risk period for the event starts before the beginning of the study period. In both right- and left-censored cases, some information about individual survival time is known, but exact survival time is unknown (Kleinbaum 1997). Cases may be censored either way, or both ways. Teachman (1982) notes that an important property of any statistical technique being used to analyze data on marital histories and dissolution is its ability to handle truncated observations. There is still important information to be had from cases where survival time is not fully known. The PH model has the ability to include what information is known from censored cases.

Since retrospective data were collected in GSS-95, there is no possibility of left censoring. Respondents were asked to recall all previous unions they had been involved in. There is also no issue with right censoring due to loss of respondent to the study. Censored data does, however, include all cases in which the respondent had not experienced the event of interest at the time of the survey, i.e., the first marriage had not dissolved by separation or divorce. Cases in which 
the first marriage had ended due to death of the spouse are censored, since the total survival time until marital dissolution is unknown. There are 1,030 of such cases, or $14.3 \%$ of the 7,187 first marriages. In total, there are 5,756 (80.1\%) censored cases and 1,431 (19.9\%) non-censored cases.

The dependent variable in the analyses is duration until marital dissolution (i.e., time to dissolution due to divorce or separation). Cases in which the respondent cohabited with the marital partner before marriage are treated as a single union; the duration is then measured from the start of the cohabitation. The current study will continue to treat these cases as such, rather than as two separate unions, in keeping with the research of DeMaris and Rao (1992) and Teachman and Polonko (1990). The principal covariate, marital union type, therefore consists of two categories: (1) "marriage only, no cohabitation" (reference), and (2) "marriage preceded by cohabitation."

In the multivariate analyses we control for several demographic, cultural, and socioeconomic variables. Age cohort is divided into four age groups, corresponding (in 1995) with pre-baby boom (50 and over), early baby boom (40-49), late baby boom (30-39), and post-baby boom (15-29). Generally, cohabitors tend to be young. The more recent the cohort the individual comes from, the more likely he or she is to have ever cohabited (Bumpass and Sweet 1989; Burch 1989; LeBourdais et al. 2000; Nock 1995; Schoen 1992). Few people who formed unions prior to the 1970s entered first into cohabitation before marriage. Therefore we would expect that marital instability, related to premarital cohabitation, would become strongly evident in the early baby boom cohort, the first group of young adults to experience not only the dramatic rise in cohabitation in the 1970s, but also the liberalization of the Canadian divorce laws in 1968. Currently, most people from older cohorts who are cohabiting are doing so after a previous divorce or separation (Burch 1989).

Additional covariates are age at start of union, age heterogamy, frequency of religious attendance, education level, presence of children in household, respondent's experience with parental marital breakdown, experience of spouse with previous cohabitation, contraceptive use, and region of residence (i.e. Quebec province vs. other province). Research has provided evidence that each of these variables is associated with marital instability (Morgan and Rindfuss 1985; Oppenheimer 1988; Hall and Zhao 1995; Balakrishnan et al. 1987, 1993; Balakrishnan and Chen 1990; Thornton, Axinn, and Hill 1992; Wu 2000; Cherlin 1990; Cherlin, Kiernan, and Chase-Lansdale 1995; Bumpass, Sweet, and Cherlin 1991; Nock 1995; Burch 1989; LeBourdais, Neill and Vachon 2000; Manning and Smock 1995; Dumas and Bélanger 1997; Pollard and Wu 1998). 
Ronald A. Budinski and Frank Trovato

All covariates in the PH models are coded 1 if true (yes), zero if not (no). Dummy variables are used for covariates with more than two categories. Each covariate contains one reference category that is coded zero in all cases. The percentage distribution of the covariates, for men and women, can be found in Appendix A; distributions are based on standardized weighted data ${ }^{5}$.

\section{Results}

Table 1 presents initial results for the PH model (Model 1). The event of interest is marital dissolution by separation or divorce. The hazard function, $\mathrm{e}^{\circledR i}$, represents the probability of marital dissolution occurring at marital (or cohabitation plus marital) duration $t$. Model 1, and each subsequent PH model (Tables $2-4$ ), was tested separately for each sex, as the results were expected to differ by sex for certain covariates. The time function for the time-varying covariate Marital Union Type is simply a linear function $t$, measured in years. The dummy variable coding of the covariate Age Cohort resulted in the covariate being a linear function of other covariates and consequently the reference age category was automatically eliminated in the analysis for female respondents, with the next-to-oldest age category substituted as the reference. Therefore, we removed this variable in our subsequent PH models.

The main result of Model 1 shown in Table 1 is that there appears to be no difference in the hazard of marital dissolution by separation or divorce between premarital cohabitors and non-cohabitors, either among men or women, when all covariates are included in the analysis. With non-cohabitors having a reference value of 1.0, cohabiting men and women have non-significant hazards of marital dissolution of only $0.004(0.4 \%)$ more and $0.006(0.6 \%)$ less, respectively, holding all other covariates constant. The interaction of Marital Union Type with time indicates that the difference in dissolution risk between the two marital types is negligible and unchanging throughout marriage.

With the exception of Age Cohort few covariate categories show significant hazard ratios in this first $\mathrm{PH}$ model. Younger age is strongly associated with marital instability, as we would expect. The effect is especially pronounced for men---those who were less than 30 years of age at the time of the survey were almost 8 times more likely to dissolve their marriage than men age 50 and over. Women under 30 , on the other hand, have a risk of dissolution slightly more than twice as large as the risk for women age 50 and over.

Looking at the other covariates in Table 1, we see that women who are five or more years older than their husbands have a hazard of marital dissolution fourand-a-half times greater than in cases where the wife and husband are the same 
age. Men with some post-secondary education have more than an $80 \%$ greater risk of dissolution compared with university-educated men. Both men and women who never attend religious service have risks of marital dissolution that are $83 \%$ and $100 \%$ greater, respectively, than those who attend at least once per week, although the result is only significant for women. Curiously, lack of children in the household seems to increase likelihood of marital dissolution very strongly for men, but has little effect on the hazard of dissolution for women. Although the resulting hazard ratios for both sexes are non-significant in this covariate, males with no children present in the household have a dissolution hazard that is 3.5 times greater than males with children present.

As far as the remaining covariates are concerned, they appear to influence the risk of dissolution significantly only among female respondents. For example, the experience of a parental marital breakdown increases the hazard of marital breakdown among female offspring by over 80 percent, but does not significantly affect marital outcomes among male offspring. For women, the hazard is reduced when contraceptives are used in the marriage. And there is more than a $60 \%$ greater risk of marital breakdown if a woman's husband had once cohabited with another person.

The evidence in this initial PH model showing no effect on the stability of marriage by premarital cohabitation contradicts most of the earlier research on the subject. However, when the covariates Age Cohort and Contraceptive Use were excluded from the PH model, the association between cohabitation and marital dissolution became statistically significant. Results for this reduced model (Model 2) can be seen in Table 2.

Premarital cohabitors now have a small but significantly higher risk of marital dissolution than do non-cohabitors. There is only a $3.7 \%$ greater risk of marital breakdown for male cohabitors and a $2.4 \%$ greater risk for female cohabitors. The negative relationship between age at the start of the union and marital stability has been strengthened from the full model, for both men and women. Model 2 provides clear evidence that younger age at the start of the first union tends to result in a greater likelihood of marital dissolution.

Significant hazard ratios below unity provide evidence of a strong negative relationship between educational attainment and marital stability. For men this is only true for the lowest level of educational attainment, but it is true for almost all levels below university degree for women, which lends support to the theories of Becker (1981) - women with higher education have greater access to well-paying jobs, and consequently more economic independence. These women would then have more to gain and less to lose by exiting a marriage, than do women with lower education levels. 
Ronald J. Budinski and Frank Trovato

Table 1. Hazards of Marital Dissolution for Men and Women, Full Model (Model 1)

\begin{tabular}{|c|c|c|c|c|c|c|}
\hline \multirow{3}{*}{ Covariate } & \multicolumn{3}{|c|}{ Men } & \multicolumn{3}{|c|}{ Women } \\
\hline & \multicolumn{3}{|c|}{ Hazard Ratio } & \multicolumn{3}{|c|}{ Hazard Ratio } \\
\hline & B & $\operatorname{Exp}(\boldsymbol{B})$ & S.E. & B & $\operatorname{Exp}(\boldsymbol{B})$ & S.E. \\
\hline \multicolumn{7}{|l|}{ Marital Union Type ? t } \\
\hline (Marriage only) & & 1.000 & & & 1.000 & \\
\hline \multicolumn{7}{|l|}{ Age Cohort } \\
\hline $15-29$ & 2.054 & $7.798 * *$ & 0.617 & 0.811 & 2.251* & 0.330 \\
\hline $30-39$ & 1.597 & $4.941 * *$ & 0.440 & 0.657 & $1.928 * *$ & 0.161 \\
\hline $40-49$ & 1.250 & $3.490 *$ & 0.396 & -- & 1.000 & -- \\
\hline ( 50 or older) & & 1.000 & & & & \\
\hline \multicolumn{7}{|l|}{ Age of Respondent at Start of Union } \\
\hline Less than 20 years & 0.070 & 1.073 & 0.292 & 0.179 & 1.196 & 0.243 \\
\hline $20-21$ & 0.299 & 1.348 & 0.261 & -0.293 & 0.746 & 0.248 \\
\hline $22-24$ & 0.010 & 1.011 & 0.236 & -0.116 & 0.891 & 0.237 \\
\hline ( 25 or older) & & 1.000 & & & 1.000 & \\
\hline \multicolumn{7}{|l|}{ Age Difference Between Respondent and Spouse } \\
\hline (No difference) & & 1.000 & & & 1.000 & \\
\hline Respondent $1-5$ years older & 0.359 & 1.431 & 0.222 & 0.231 & 1.260 & 0.273 \\
\hline Respondent $>5$ years older & 0.355 & 1.427 & 0.396 & 1.505 & 4.504* & 0.751 \\
\hline Respondent $1-5$ years younger & 0.229 & 1.258 & 0.297 & -0.132 & 0.876 & 0.169 \\
\hline Respondent $>5$ years younger & -0.010 & 0.990 & 0.639 & 0.011 & 1.011 & 0.213 \\
\hline \multicolumn{7}{|l|}{ Education Level of Respondent } \\
\hline Less than high school diploma & 0.338 & 1.403 & 0.287 & -0.433 & 0.648 & 0.253 \\
\hline High school diploma & 0.453 & 1.573 & 0.298 & -0.359 & 0.698 & 0.244 \\
\hline Some post-secondary & 0.595 & $1.814 *$ & 0.284 & 0.070 & 1.072 & 0.230 \\
\hline Diploma from Comm. College, tech./vocational school & 0.348 & 1.416 & 0.265 & -0.180 & 0.835 & 0.212 \\
\hline (University degree) & & 1.000 & & & 1.000 & \\
\hline \multicolumn{7}{|l|}{ Canadian Region of Residence } \\
\hline Quebec & 0.017 & 1.018 & 0.183 & 0.149 & 1.161 & 0.137 \\
\hline (Canada less Quebec) & & 1.000 & & & 1.000 & \\
\hline \multicolumn{7}{|l|}{ Frequency of Religious Attendance } \\
\hline (At least once a week) & & 1.000 & & & 1.000 & \\
\hline At least once a month & 0.390 & 1.476 & 0.356 & -0.030 & 0.971 & 0.250 \\
\hline One or more times a year & 0.464 & 1.591 & 0.285 & 0.300 & 1.350 & 0.208 \\
\hline Not at all & 0.714 & 2.042 & 0.269 & 0.607 & $1.834 *$ & 0.205 \\
\hline \multicolumn{7}{|l|}{ Children Present in Household } \\
\hline (Yes) & & 1.000 & & & 1.000 & \\
\hline No & 1.256 & 3.512 & 0.183 & 0.245 & 1.278 & 0.145 \\
\hline \multicolumn{7}{|l|}{ Parents had Separated or Divorced } \\
\hline Yes & 0.444 & 1.559 & 0.233 & 0.636 & $1.888 * *$ & 0.161 \\
\hline (No) & & 1.000 & & & 1.000 & \\
\hline \multicolumn{7}{|l|}{ Respondent and/or Spouse Using Contraceptive } \\
\hline Yes & 0.252 & 1.287 & 0.177 & -0.588 & $0.555 * *$ & 0.163 \\
\hline (No) & & 1.000 & & & 1.000 & \\
\hline \multicolumn{7}{|l|}{ Spouse had Cohabited with Another Person } \\
\hline Yes & 0.377 & 1.459 & 0.339 & 0.502 & $1.651 *$ & 0.208 \\
\hline (No) & & 1.000 & & & 1.000 & \\
\hline$-2 \mathbf{L L}$ & & 634.045 & & & 738.766 & \\
\hline \multicolumn{7}{|l|}{ () Indicates reference categories. } \\
\hline $\begin{array}{l}* p<0.05 \\
* * p<0.01\end{array}$ & & & & & & \\
\hline & & & & & & \\
\hline
\end{tabular}


Ronald A. Budinski and Frank Trovato

The effect of religious attendance on the hazard of marital breakdown appears to be stronger in the reduced model than it was in Model 1. Infrequent or nonattendees are two to three times more likely to experience a marital dissolution than those who attend church on a regular, weekly basis. This relationship becomes more apparent once age is no longer controlled for in the model, because regular religious attendance is most common among older age groups, those that had been socialized in a less secular and individualistic atmosphere.

In Table 2 there is also a stronger positive effect of parental divorce on daughters' likelihood of marital breakdown. For the male respondents the chance of marital breakdown has not changed from the full model. Also, it can be seen that marital breakdown is about three times more likely if one's spouse had previously cohabited with another person, than if the spouse had never cohabited.

One important change from the full model (Table 1) is that persons residing in Quebec show a significantly higher dissolution hazard compared to other Canadians, once age is no longer controlled for. The risks for men and women in Quebec are about $46 \%$ and $27 \%$ greater, respectively, than they are for men and women outside Quebec.

Age heterogamy still has no significant influence on marital stability for men in Model 2. However, the value of the hazard ratio for women who are 1-5 years younger than their husbands is 6.04 , a dramatic increase from the value in the full multivariate models. This unusually high value contradicts what we would intuitively expect, but it has a very large standard error, and should therefore not be given too much importance.

We have seen that having children in the household affects men and women differently in their propensity to dissolve their marriage, and in ways we might not expect. Model 1 showed that the lack of children in the household increases the likelihood of marital dissolution, especially for men, although the hazard ratios for this covariate are non-significant. In the current model, the hazard ratios have dropped for both sexes but are now significant. For men, the ratio of 1.805 indicates an $80 \%$ greater risk of marital dissolution by separation or divorce when children are not present, but for women the ratio is 0.772 , indicating a lower risk of dissolution in the absence of children in the household. In other words, the dissolution risk is about $30 \%$ greater for women when children are present in the household.

Table 3 provides further results of this relationship on four groups. The single covariate, Presence of Children in Household, is tested separately by gender, and by age groups of less than 40 and 40 and over. The results show that having 
children at home acts as a deterrent to marital dissolution among male respondents of all ages and among female respondents under age 40. The lack of children at home deters marital discord among female respondents age 40 and over. Children's integrative role in marriage is lower overall for women than for men. Also, men age 40 and over show a much lower likelihood of marital dissolution when children are not present at home than men under age 40 do. It is possible that both husbands and wives feel strongly about keeping their marriage together "for the sake of the children" when their children are young and still living at home. Once couples get older, they may feel less obliged to remain in a troubled marriage if there are still children present in the household. Older women with children still at home may in fact be more likely to exit a troubled marriage, a result possibly of greater female economic independence, which also tends to increase with age. Men and women perhaps view the role of marriage in the context of childbearing and child rearing differently. Also, the integrative role of children on marital stability seems to deteriorate with older age of the couple, presumably once children have passed the childhood stage. Further research should be conducted to further explore these types of interrelationships.

Table 3

Cox PH Models Testing Presence of children in the Household by Age Group and Sex

\begin{tabular}{|c|c|c|c|c|}
\hline & \multicolumn{2}{|c|}{ Age $<40$} & \multicolumn{2}{|c|}{ Age 40 and over } \\
\hline & Men & Women & Men & Women \\
\hline Beta & 1.958 & 0.810 & 0.284 & -0.323 \\
\hline $\begin{array}{l}\text { Hazard Ratio } \\
(\exp (ß))\end{array}$ & $7.084 * *$ & $2.247 * *$ & $1.329 * *$ & $0.724 * *$ \\
\hline Standard Error & 0.195 & 0.164 & 0.112 & 0.095 \\
\hline -2 Log Likelihood & $1,276.747$ & $2,796.160$ & $5,637.512$ & $7,975.575$ \\
\hline \multicolumn{5}{|l|}{$95 \%$ C. 1 on $\exp (\beta)$} \\
\hline Lower & 4.830 & 1.628 & 1.068 & 0.601 \\
\hline Upper & 10.391 & 3.102 & 1.654 & 0.872 \\
\hline $\mathrm{N}$ (event) & 112 & 219 & 386 & 525 \\
\hline $\mathrm{N}$ (censored) & 793 & 1,045 & 1,549 & 2,145 \\
\hline
\end{tabular}


Ronald A. Budinski and Frank Trovato

Recall that Model 1 (in Table 1) indicated no effect of premarital cohabitation on marital stability. With the covariate Marital Union Type interacting with time, it would appear that the effect of premarital cohabitation remains negligible throughout the course of marriage. Yet when the age-related covariates were removed from the model, a slight positive effect of cohabitation on likelihood of marital dissolution appeared. Is it possible that there is in fact a differential cohabitation effect on marriage determined by length of the union?

As was suggested earlier, one way to measure this possible effect would be to divide marital duration into a series of intervals, and assume that the hazard of dissolution remains constant within each interval but differs between intervals. This method assigns the time function $g(t)$ within the time interval $\left(t_{0}, t_{1}\right)$ the value of 1 when $t_{0}<t<t_{1}$, and zero otherwise. Because of the possibility of small sample sizes, the number of intervals is limited to two. In other words, there are two time functions $g_{1}(t)$ and $g_{2}(t)$ such that $g_{1}(t)=1$ if $t<t_{0}$ and 0 if $t=$ $t_{0}$, and $g_{2}(t)=1$ if $t=t_{0}$ and 0 if $t<t_{0}$. This study will follow the findings of Teachman and Polonko (1990) and set the hypothetical dividing point $t_{0}$ at 10 years from the start of the union (premarital cohabitation or marriage). However, these authors found that premarital cohabitors experienced a greater propensity than non-cohabitors to dissolve their marriage only after ten years. This study expects the opposite: cohabitors who marry are more likely than married couples who did not cohabit to dissolve their marriage, but after ten years of marriage, the difference in hazards between the two groups decreases to non-significance, once the less stable marriages have been "weeded out" early on. The full model will be revised as model 3 to include two covariates for marital union type, one multiplied by $g_{1}(t)$ and the other multiplied by $g_{2}(t)$. Results of these models are given in Table 4.

There is clearly a premarital cohabitation effect for the interaction of marital union type with the time function $g_{1}(t)$, in which union duration is less than ten years. The hazard ratios for both sexes are significant and above 2.0, indicating that premarital cohabitors are more than twice as likely to dissolve their marriage dissolving during its early years than non-cohabitors are. At ten or more years into the union, the hazard ratios drop below unity, which would indicate a lower likelihood of marital dissolution among cohabitors than among non-cohabitors (however, due to the rather small number of observations in which premarital cohabitors have been married as long as ten years, these estimates must not be considered very reliable). It is possible that these opposing effects of premarital cohabitation, depending on whether the duration of marriage is lass than or more than 10 years, cancelled each other out in Model 1, 
The Effect of Premarital Cohabitation on Marital Stability over the Duration of Marriage

Table 4. Hazards of Marital Dissolution for Men and Women, Full Model with Time Function (Model 3)

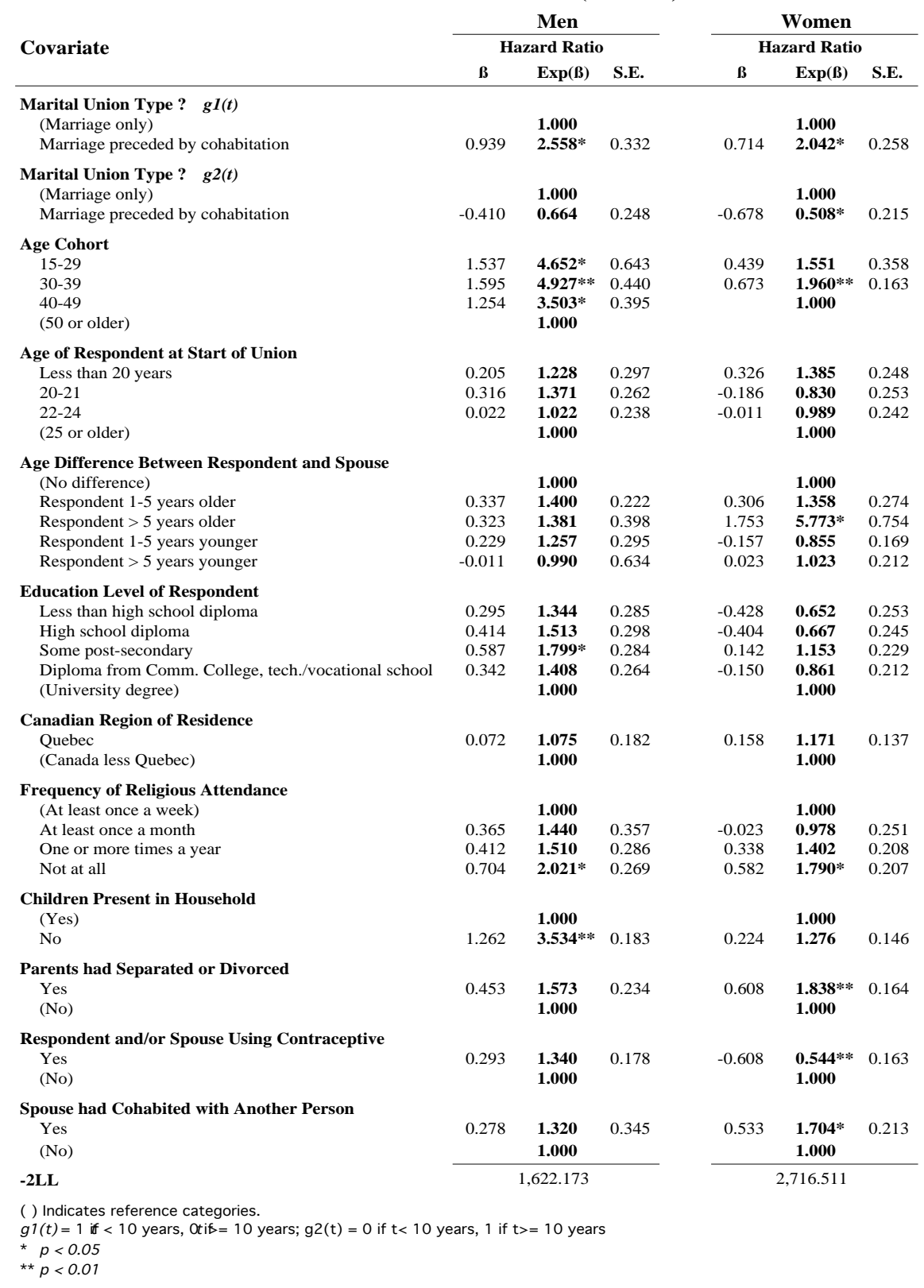


Ronald A. Budinski and Frank Trovato

where we saw that the hazard ratios for premarital cohabitors and noncohabitors were basically equal.

The relationships of the categories of the other covariates in the model with marital stability are, for the most part, unchanged from Model 1. Most of the significant and non-significant categories remain so in the current model, though the values of some have changed from the previous models. There are still few significant effects on marital stability from covariates such as Age Heterogamy, Education Level, and Canadian Region of Residence. The remaining covariates show hazard ratios in one or more categories that are significantly large or small, as they were in Model 1 (Table 1).

\section{Discussion}

Studies have shown that couples living together prior to marriage have a greater risk of their marriage dissolving than couples that do not. Only a handful of these studies have given some attention to what happens throughout duration of marriage with cohabitors and non-cohabitors, although this was not their main focus of analysis. We sought to investigate further the issue of cohabitation's impact on marital stability throughout marital duration, based on Canadian data. We asked: How might the effect of cohabitation change over time? Does it increase, leading to greater likelihood of marital breakdown as marriage goes on, or does it dissipate? Why would there be such a change over time? What other variables are related to marital instability, and do they also affect the relationship of premarital cohabitation and risk of marital breakdown?

With the use of Proportional Hazards models, we attempted to measure the effect of cohabitation on marital stability, particularly how it interacts with time spent in marriage. When we controlled for several covariates that had been found to affect marital stability, we found that the cohabitation effect was basically nil, even when measured as an interaction with time spent in the union. Only after the removal of Age Cohort and Contraceptive Use from the model did the null hazard for premarital cohabitation change to a small but significant positive hazard. This suggested that age cohort in particular is highly correlated with most of the other covariates in our model. Thus age explains a great deal of the association between premarital cohabitation and marital instability, the reason being that cohabitation is practiced mainly by young adults, but at the same time, both cohabiting and marital unions have become less stable among these young age cohorts. Being born and raised in an atmosphere of individualism and self-fulfillment, the post-War birth cohorts have accepted alternatives to the traditional family pattern, like cohabitation, but are also more willing to end unions (marital or cohabiting) that do not work for them. 
A strong cohabitation effect became evident in a $\mathrm{PH}$ model that included interactions of Marital Union Type with two time functions, to designate if the duration of the union had lasted less than ten years, or at least ten years. Compared with married persons who did not cohabit, premarital cohabitors experienced a greater marital dissolution risk up until ten years into their union, but a lower risk from ten years on. This contradicts the results of $\mathrm{Wu}$ (2000), who found that the gap in the risk of marital disruption between cohabitors and non-cohabitors in Canada remains basically constant over time.

Our results agree in part with the bulk of research that has investigated the cohabitation effect through marital duration. Most of these studies did find that premarital cohabitors are at the greatest risk of their marriage breaking up in the early years of marriage. Once the less stable marriages between cohabitors have been dissolved early on, the dissolution risks for cohabitors and non-cohabitors become similar (Bennett, Blanc and Bloom, 1988; Lillard, Brien and Waite 1995; Schoen 1992). Teachman and Polonko's study (1990) found no significant effect on dissolution among cohabitors, once marital duration was controlled for, and DeMaris and Rao (1992) noticed that the likelihood of dissolution was always higher for persons who cohabited before marriage, regardless of marital duration. It was never found in any of these studies that cohabitation before marriage actually works in favor of marital stability, at any point in marriage ${ }^{6}$.

Our results suggest there is an association between premarital cohabitation and marital instability, but the strength and direction of that association are not constant throughout marriage. At least for the first ten years in marriage, cohabitors face a greater risk that their marriage will dissolve than noncohabitors do. After ten years, the risk of dissolution faced by cohabitors is reduced. This risk may even be lower than the risk faced by non-cohabitors, although the results from this study are not conclusive. Any future research on premarital cohabitation should therefore take into account marital duration and age/birth cohort factors when analyzing the effect on marital stability. Moreover, the hazard of marital dissolution is larger for younger cohorts than for older cohorts. And as long as age is not controlled for statistically, the hazard of marital breakdown is higher when (1) one experiences their own parents' marital breakdown, (2) one is a resident of Quebec, (3) one's level of religiosity, as measured by frequency of religious attendance, is low, (4) one's spouse had cohabited previously with another person, and (5) contraceptive use was practiced (women only).

There are aspects of cohabiting relationships that were out of the scope of this study, although they may bear some relationship to subsequent instability of marriage. For instance, there is an increasing propensity of people to engage in serial cohabitation; that is, to enter into and exit out of several cohabiting 
relationships over the course of their adult lives. Some of these relationships may end in marriage. We leave it to future studies to study the effect on marriage of multiple cohabiting relationships, where longitudinal data would be most valuable. This type of data would also be best to gain insight into the "experience" theory of cohabitation, where changing attitudes toward marriage, separation and divorce may be captured.

This study has helped to further understand the cohabitation phenomenon in Canada. Canadians who have lived with their spouse before entering marriage seem to fit the description of cohabitors, as developed in American and European research. They are mainly young adults whose attitudes and values are not as traditional as those of their non-cohabiting counterparts. Although most cohabitors who make the transition to marriage no doubt intend the marriage to be permanent, the results of our analyses suggest that cohabitation's effect on marital stability varies throughout the course of marriage. For example, when considering short marital durations, premarital cohabitation leads to a greater risk of marital dissolution, while for longer marital durations, premarital cohabitation leads to a reduced risk of marital dissolution.

Finally, on a broader sociological scale, this analysis suggests that while cohabitation continues to select people with certain characteristics and attitudes that are not as common among non-cohabitors, cohabitation is clearly more common among young adults. However, as the population ages, cohabitation will spread into older age cohorts, and we may no longer see any special selective characteristics among people who choose to cohabit. When that happens, there may be no theoretical reason for assuming that marriages preceded by cohabitation would be any more or any less stable than marriages without cohabitation.

\section{Acknowledgements:}

Paper presented at the annual meetings of the Canadian Population Society, University of Toronto, May 30 - June 1, 2002. The authors wish to thank the anonymous referees for their thoughtful and helpful comments for revision.

\section{End Notes:}

1. Currently, cohabitation is more likely to lead to marriage in North America than in Western Europe, where separation is usually the end result. An exception in North America is the province of Quebec, which tends to follow the European model. The differences in Western European and 
North American patterns of cohabitation illustrate two major conceptualizations of the relationship: (1) a final stage in the process leading to marriage (or a form of "trial marriage"), and (2) a substitute for marriage (Rindfuss and VandenHeuvel 1990). The first conceptualization is dominant in the United States and, to a lesser degree, in Canada (Axinn and Thornton 1992; Bennett et al. 1988; DeMaris and Rao 1992; Pollard and Wu 1998; Rao 1988; Wu and Balakrishnan 1995), while the second conceptualization is more common in Western Europe.

2. Further lending support to the "experience" theory, Thomson and Colella (1992) found that couples who cohabit at least a year before marriage believe that divorce is more likely than couples who cohabit less than a year before marriage. Axinn and Barber (1997) found evidence that enthusiasm toward marriage and childbearing declines with number of months spent in a cohabiting relationship. And, according to Axinn and Thornton (1992), a feedback effect takes place, whereby the rising divorce rate acts to encourage couples' preference to cohabit before marriage, which in turn increases acceptance of and likelihood of divorce.

3. Data for GSS-95 were collected monthly throughout all twelve months of 1995 , in order to evenly represent the seasonal variation in information gathered. Computer-assisted telephone interview (CATI) technology was employed in the collection process, which unfortunately excludes households without a telephone. However, these households represented less than $2 \%$ of the target population in 1995, and survey estimates have been weighted to account for individuals without telephones.

4. When covariates are all time-independent, the hazard function can be written as:

$$
\begin{aligned}
h(t, \mathbf{X}) & =h_{0}(t) \exp \left(\beta_{1} \mathrm{X}_{1}+\beta_{2} \mathrm{X}_{2}+\ldots+\beta_{\mathrm{k}} \mathrm{X}_{\mathrm{k}}\right) \\
= & h_{0}(t) \exp (\hat{\beta} \mathrm{X}),
\end{aligned}
$$

where $B$ is a column vector of $k$ coefficients and $X$ is a row vector of $k$ covariates. The quantity $h_{0}(t)$ is an arbitrary duration-dependent baseline hazard function associated with a baseline or reference group, in which all covariates in the model take the value of zero. $h_{0}(t)$ is the equivalent of the constant in least-squares regression, but one that takes different values at each time $t$ (Teachman 1982). 
Ronald A. Budinski and Frank Trovato

A hazard ratio may be used to compare the hazard estimate of one covariate category with another, holding all other categories constant. Typically, a reference category for each covariate is selected for comparison. The hazard ratio is the value of:

$$
\frac{h\left(t, \mathbf{X}^{*}\right)}{h(t, \mathbf{X})}
$$

Where $\mathbf{X}^{*}$ and $\mathbf{X}$ contain the values of the category of interest and reference category, respectively, for the $i^{\text {th }}$ covariate (i.e. $\mathrm{X}_{i}{ }^{*}$ and $\mathrm{X}_{i}$ ). The ratio may then be simplified to

$$
H R=\exp \left[\beta_{i}\left(\mathrm{X}_{i}^{*}-\mathrm{X}_{i}\right)\right]
$$

In the present study $\mathrm{X}_{i}{ }^{*}$ and $\mathrm{X}_{i}$ are given values of 1 and zero, respectively, for all $i$, which simplifies the hazard ratio further to $\mathrm{e}^{\boldsymbol{B} \boldsymbol{i}}$. From the hazard ratio, a simple transformation, $100 \cdot\left(\mathrm{e}^{5} i_{1} i_{1}\right.$ expresses the percentage difference in the hazard of the event of interest occurring for a specific category of covariate $i$ compared with the reference category, holding all other variables constant ( $\mathrm{Wu} 2000$ ). If the hazard ratio is less than unity, the transformation may be calculated as $100 \cdot\left[\left(1 / \mathrm{e}^{[\tilde{f} i}.\right)-1\right]$

5. Standardization of weights was computed by dividing the value of the weights provided in the GSS-95 (variable WGHTFNL) by the average of these weights for all cases used in the analysis (i.e. all cases in which a first marriage is reported). The purpose and method of weight standardization is to take into account the complex stratification and clustering of the sample's design and also the unequal probabilities of selection of respondents (Statistics Canada 1997: 17).

6. As previously noted, White's (1987) research in Canada on the effect of premarital cohabitation on later marital stability, did find just this sort of relationship: the likelihood of staying married was greater for those who cohabited beforehand, once age at marriage and length of marriage was controlled for. Subsequently, Trussell and Rao (1989) discredited White's finding by pointing out a fatal error in White's methodology that led him to make an incorrect conclusion. 


\section{References:}

Axinn, William G. and Jennifer S. Barber. 1997. "Living arrangements and family formation attitudes in early adulthood." Journal of Marriage and the Family 59(3): 595-611.

Axinn, William G. and Arland Thornton. 1992. "The relationship between cohabitation and divorce: selectivity or causal influence?" Demography 29(3): 357-74.

Axinn, William G. and Arland Thornton. 1996. "The influence of parents' marital dissolutions on children's attitudes toward family formation. Demography 33(1): 66-81.

Balakrishnan, T.R., and Jiajian Chen. 1990. "Religiosity, nuptiality and reproduction in Canada." Canadian Review of Sociology and Anthropology 27(3): 316-40.

Balakrishnan, T.R., Evelyne Lapierre-Adamcyk, and Karol J. Krotki. 1993. Family and Childbearing in Canada: A Demographic Analysis. Toronto: University of Toronto Press.

Balakrishnan, T.R., K. Vaninadha Rao, Evelyne Lapierre-Adamcyk, and Karol J. Krotki. 1987. "A hazard model analysis of the covariates of marriage dissolution in Canada." Demography 24(3): 395-406.

Becker, Gary S. 1981. A Treatise on the Family. Cambridge, Mass.: Harvard University Press.

Bennett, Neil G., Ann Klimas Blanc, and David E. Bloom. 1988. "Commitment and the modern union: assessing the link between premarital cohabitation and subsequent marital stability." American Sociological Review 53(1): $127-38$

Booth, Alan and David Johnson. 1988. "Premarital cohabitation and marital success." Journal of Family Issues 9(2): 255-72.

Bumpass, Larry L. and James A. Sweet. 1989. "National estimates of cohabitation." Demography 26(4): 615-25. 
Ronald A. Budinski and Frank Trovato

Bumpass, Larry L., James A. Sweet, and Andrew Cherlin. 1991. "The role of cohabitation in declining rates of marriage." Journal of Marriage and the Family 53(4): 913-27.

Burch, Thomas K. 1989. "Common-law unions in Canada: a portrait from the 1984 Family History Survey." In The Family in Crisis: A Population Crisis? Jacques Légaré, T.R. Balakrishnan, and Roderick P. Beaujot, ed. Ottawa: Lowe-Martin Company Inc.

Cherlin, Andrew. 1990. "Recent changes in American fertility, marriage, and divorce." Annals of the American Academy of Political \& Social Science 510: $145-154$.

Cherlin, Andrew, Kathleen E. Kiernan, and P.Lindsay Chase-Lansdale. 1995. "Parental divorce in childhood and demographic outcomes in young adulthood." Demography 32(3): 299-318.

Cox, D.R. 1972. "Regression models and life tables." Journal of the Royal Statistical Society, Series B 34(2): 187-220.

DeMaris, Alfred and K. Vaninadha Rao. 1992. "Premarital cohabitation and subsequent marital stability in the United States: a reassessment." Journal of Marriage and the Family (1): 178-90.

Dumas, Jean, and Alain Bélanger. 1997. "Common-law unions in Canada at the end of the $20^{\text {th }}$ century." in Report on the Demographic Situation in Canada 1996. Statistics Canada Catalogue No. 91-209-XPE. Ottawa: Statistics Canada.

Hall, David R., and John Z. Zhao.1995. "Cohabitation and divorce in Canada: testing the selectivity hypothesis." Journal of Marriage and the Family 57(2): 421-27.

Hinde, Andrew. 1999. Demographic Methods. London: Arnold Publishers.

Kleinbaum, David G. 1997. Survival Analysis: A Self-learning Text. New York, NY. Springer-Verlag New York Inc.

LeBourdais, Céline, Ghyslaine Neill, and Nathalie Vachon. 2000. "Family disruption in Canada: impact of the changing patterns of family formation and of female employment." Canadian Studies in Population 27(1): 85105. 
Lillard, Lee A., Michael J. Brien, and Linda J. Waite. 1995. "Premarital cohabitation and subsequent marital dissolution: a matter of selfselection?" Demography 32(3): 437-57.

Manning, Wendy D., and Pamela J. Smock. 1995. "Why marry? Race and the transition to marriage among cohabitors.” Demography 32(4): 513-20.

Mills, Melinda, and Frank Trovato. 2000. "The effect of pregnancy in cohabiting unions on marriage in Canada, the Netherlands and Latvia." Statistical Journal of the United Nations Economic Commission for Europe 18: 103-18.

Morgan, S. Philip, and Ronald R. Rindfuss. 1985. "Marital disruption: structural and temporal dimensions." American Journal of Sociology 90(5): 105577.

Newcomb, Michael D., and Peter M. Bentler. 1980. "Cohabitation before marriage: a comparison of married couples who did and did not cohabit." Alternate Lifestyles 3(1): 65-85.

Nock, Steven L. 1995. “A comparison of marriages and cohabiting relationships.” Journal of Family Issues 16(1): 53-76.

Oppenheimer, Valerie Kincade. 1988. “A theory of marriage timing.” American Journal of Sociology 94(3): 563-91.

Pollard, Michael S., and Zheng Wu. 1998. "Divergence of marriage patterns in Quebec and elsewhere in Canada." Population and Development Review 24(2): 329-56.

Rao, K.V. 1988. "Marriage risks, cohabitation and premarital births in Canada." European Journal of Population 6(1): 27-49.

Rindfuss, Ronald R., and Audrey VandenHeuvel. 1990. “Cohabitation: a precursor to marriage or an alternative to being single?" Population and Development Review 16(4): 703-26.

Schoen, R. 1992. "First unions and the stability of first marriages." Journal of Marriage and the Family 54(2): 281-284.

Smock, Pamela J. 2000 "Cohabitation in the United States: Appraisal of research themes, findings, and implications." Annual Review of Sociology 26: $1-20$. 
Ronald A. Budinski and Frank Trovato

Statistics Canada. 1997. General Social Survey, Cycle 10: The Family: Public Use Microdata File Documentation and User's Guide. Catalogue No. 12M0010-GPE. Ottawa: Statistics Canada.

Teachman, Jay D. 1982. "Methodological issues in the analysis of family formation and dissolution." Journal of Marriage and the Family 44(4): 1037-53.

Teachman, Jay D. and Karen A. Polonko. 1990. "Cohabitation and marital stability in the United States." Social Forces 69(1): 207-20.

Thomson, Elizabeth, and Ugo Colella. 1992. "Cohabitation and marital stability: quality or commitment?" Journal of Marriage and the Family 54(2): 25967.

Thornton, Arland, William G. Axinn, and Daniel H. Hill. 1992. "Reciprocal effects of religiosity, cohabitation, and marriage." American Journal of Sociology 98(3): 628-51.

Trussell, James, and K.V. Rao. 1989. "Premarital cohabitation and marital stability: A reassessment of the Canadian evidence." Journal of Marriage and the Family 51(2): 535-40.

White, James M. 1987. "Premarital cohabitation and marital stability in Canada." Journal of Marriage and the Family 49(3): 641-47.

Wu, Zheng. 2000. Cohabitation: An Alternative Form of Family Living. Don Mills, Ont.: Oxford University Press.

Wu, Zheng and T.R. Balakrishnan. 1995. "Dissolution of premarital cohabitation in Canada." Demography 32(4): 521-3 
The Effect of Pemaital Cohabitation on Marital Stability over the Duration of Marriage

\section{Appendix A. Percentage Distribution of Selected Covariates,} Men and Women, by Marital Union Type

\begin{tabular}{|c|c|c|c|c|}
\hline \multirow[b]{2}{*}{ Covariate } & \multicolumn{2}{|c|}{ Men } & \multicolumn{2}{|c|}{ Women } \\
\hline & $\begin{array}{c}\text { Marriage } \\
\text { Only }\end{array}$ & $\begin{array}{c}\text { Marriage } \\
\text { Preceded by } \\
\text { Cohabitation }\end{array}$ & $\begin{array}{c}\text { Marriage } \\
\text { Only }\end{array}$ & $\begin{array}{c}\text { Marriage } \\
\text { Preceded by } \\
\text { Cohabitation } \\
\end{array}$ \\
\hline \multicolumn{5}{|l|}{ Age Cohort } \\
\hline $15-29$ & 4.2 & 13.9 & 7.2 & 22.8 \\
\hline $30-39$ & 20.8 & 46.7 & 19.4 & 48.4 \\
\hline $40-49$ & 24.9 & 27.8 & 23.2 & 23.6 \\
\hline 50 and Over & 50.1 & 11.6 & 50.3 & 5.2 \\
\hline Total & $\overline{700.0}$ & $\overline{700.0}$ & $\overline{\overline{700.1}}$ & $\overline{700.0}$ \\
\hline \multicolumn{5}{|l|}{ Age at Start of Union } \\
\hline$<20$ Years & 5.6 & 14.3 & 26.6 & 30.8 \\
\hline $20-21$ & 16.2 & 18.6 & 25.1 & 16.9 \\
\hline $22-24$ & 33.5 & 23.9 & 25.4 & 23.1 \\
\hline 25 and Over & 44.7 & 43.2 & 22.9 & 29.2 \\
\hline Total & $\overline{700.0}$ & $\overline{\overline{7} 100.0}$ & $\overline{700.0}$ & $\overline{\overline{700.0}}$ \\
\hline \multicolumn{5}{|l|}{ Age Difference Between Respondent and Spouse } \\
\hline No difference & 21.3 & 24.5 & 19.6 & 23.8 \\
\hline Respondent $1-5$ years older & 53.3 & 51.1 & 9.3 & 8.7 \\
\hline Respondent $>5$ years older & 13.0 & 9.9 & 0.7 & 0.7 \\
\hline Respondent $1-5$ years younger & 11.0 & 11.5 & 52.3 & 50.9 \\
\hline Respondent $>5$ years younger & 1.4 & 3.0 & 18.0 & 15.8 \\
\hline Total & $\overline{\bar{\nabla} 100.0}$ & $\overline{\overline{\bar{F}} 100.0}$ & $\overline{\overline{\bar{\Sigma}} 99.9}$ & $\overline{\overline{\bar{I}} 99.9}$ \\
\hline \multicolumn{5}{|l|}{ Highest Level of Education Attained } \\
\hline Less than high school & 28.0 & 22.3 & 31.5 & 16.6 \\
\hline High school diploma & 14.4 & 16.3 & 19.3 & 19.9 \\
\hline Some post-secondary & 12.5 & 16.0 & 10.9 & 14.9 \\
\hline Diploma from Community College, Tech./Voc. School & 25.1 & 25.7 & 24.9 & 28.1 \\
\hline University degree & 20.0 & 19.7 & 13.4 & 20.5 \\
\hline Total & $\overline{\overline{700.0}}$ & $\overline{\overline{7} 100.0}$ & $\overline{\overline{7} 100.0}$ & $\overline{\overline{7} 100.0}$ \\
\hline \multicolumn{5}{|l|}{ Canadian Region of Residence } \\
\hline Quebec & 21.6 & 27.7 & 22.8 & 30.7 \\
\hline Rest of Canada & 78.4 & 72.3 & 77.2 & 69.3 \\
\hline Total & $\overline{700.0}$ & $\bar{F} 100.0$ & $\overline{700.0}$ & $\overline{700.0}$ \\
\hline \multicolumn{5}{|l|}{ Frequency of Religious Attendance } \\
\hline At least once a week & 29.9 & 10.9 & 35.0 & 16.9 \\
\hline At least once a month & 13.8 & 8.7 & 14.5 & 12.4 \\
\hline One or more times a year & 26.2 & 36.3 & 25.9 & 32.3 \\
\hline Not at all & 30.1 & 44.1 & 24.6 & 38.4 \\
\hline Total & $\overline{\overline{7} 100.0}$ & $\overline{\overline{7} 100.0}$ & $\overline{\overline{700.0}}$ & $\overline{700.0}$ \\
\hline \multicolumn{5}{|l|}{ Presence of Children in Household } \\
\hline Yes / One or more & 54.3 & 62.0 & 50.9 & 70.4 \\
\hline No & 45.7 & 38.0 & 49.1 & 29.6 \\
\hline Total & $\overline{\overline{\overline{7} 100.0}}$ & $\overline{\overline{\overline{7} 100.0}}$ & $\overline{\overline{\bar{\nabla} 100.0}}$ & $\overline{\overline{700.0}}$ \\
\hline \multicolumn{5}{|l|}{ Parents Ever Separated or Divorced } \\
\hline Yes & 9.3 & 15.5 & 8.8 & 22.0 \\
\hline No & 90.7 & 84.5 & 91.2 & 78.0 \\
\hline Total & $\overline{\nexists 100.0}$ & $\overline{700.0}$ & $\overline{700.0}$ & $\overline{700.0}$ \\
\hline \multicolumn{5}{|l|}{ Respondent and/or Spouse Using Contraceptive } \\
\hline Yes & 51.2 & 56.2 & 47.3 & 55.2 \\
\hline No & 48.8 & 43.8 & 52.7 & 44.8 \\
\hline Total & $\overline{\overline{\overline{7}} 100.0}$ & $\overline{700.0}$ & $\overline{\bar{\nabla}} 100.0$ & $\overline{\overline{7}} 700.0$ \\
\hline \multicolumn{5}{|l|}{ Spouse had Cohabited with Another Person } \\
\hline Yes & 1.2 & 12.7 & 2.2 & 18.5 \\
\hline No & 98.8 & 87.3 & 97.8 & 81.5 \\
\hline Total & $\overline{700.0}$ & $\bar{F} 100.0$ & $\bar{\nabla} 100.0$ & $\overline{700.0}$ \\
\hline
\end{tabular}

